\title{
Pregnancy with Hypoparathyroidism - A Case Report
}

\author{
Nahreen Akhtar \\ Associate Professor, Fetomaternal Medicine Wing, Dept of Obs \& Gynae, BSMMU, Dhaka
}

\begin{abstract}
There is no established therapeutic regimen for treatment of hypoparathyroidism during pregnancy. This is particularly due to uncertainty about the use of vitamin D or its analogues, as in animal experiments teratogenic side-effects have been reported. Nevertheless, vitamin D or its analogues are required to control tetany predisposing to abortion and preterm labour. I herein report the pregnancy in a hypoparathyroid woman treated with calcitriol. A 20 years old hypoparathyroid woman receiving chronic treatment with calcitriol( $0.5 \mu \mathrm{gm} /$ day) and calcium (1gm/day) was admitted in BSMMU with primi 41 weeks of pregnancy with chronic hypoparathyroidism. She had an cesarean section and delivered a healthy female baby of $3.4 \mathrm{~kg}$. Both the mother and baby were healthy.
\end{abstract}

Key words: Hypoparathyroidism, pregnancy.

[BSMMU J 2010; 3(2): 107-109]

\section{Introduction}

Chronic hypocalcemia is less common than hypercalcemia; causes include chronic renal failure, hereditary and acquired hypoparathyroidism,vitamin D deficiency, pseudo hypoparathyroidism and hypomagnesemia. Hypoparathyroidism whether hereditary or acquired, has a number of common components. Acute and chronic symptoms of untreated hypocalcemia are shared by both types of hypoparathyroidism, although typically the onset of hereditary hypoparathyroidism, is more gradual and is associated with developmental defects. In earlier decades, acquired hypoparathyroidism secondary to surgery in neck was more common than hereditary hypoparathyroidism, but the frequency of surgically induced parathyroid failure has diminished as a result of improved surgical techniques that spare the parathyroid glands and increased use of nonsurgical therapy for hyperthyroidism ${ }^{1}$.Pregnancy is associated with dynamic changes in calcium concentrations and calcitropic hormones leading to accumulation of around 30gm of fetal skeletal calcium by term. Satisfactory fetal outcomes usually are achieved with calcium and vitamin D replacement for mothers with known hypoparathyroidism. Early diagnosis and adequate calcium and vitamin D replacement may avert secondary hyperparathyroidism and fetal skeletal de-mineralisation in unrecognized cases.

Address for Correspondence: Dr. Nahreen Akhtar. Associate Professor, Fetomaternal medicine wing, Dept of Obs \&Gynae. BSMMU, Dhaka

\section{Case report}

A-20-year-old primigravida, got herself admitted in BSMMU on $2^{\text {nd }}$ August, 2009 at her 41 weeks pregnancy and known case of hypoparathyroidism for last 5 years. She recalled that she had recurrent tetanic convulsion and carpopedal spasm from her 9 years of age.The convulsion was followed by vomiting, headache and usually went into sleepy state and cannot recall the incident afterwards. The attack was occasionally associated with tongue bite but there was no incontinence of bowel and bladder. Since then she was receiving symptomatic treatment. Since 5 yrs she developed severe convulsion and admitted in Dhaka Medical College Hospital where after investigations (Ca 0.99mmol/l, Phos 2.34mmol/L, PTH $<10 \mathrm{pg} / \mathrm{ml}$ ) she was diagnosed as a case of Heriditary Hypoparathyroidism. Since then she is receiving tab calcitriol $(0.25 \mu \mathrm{g}) 1 \mathrm{tab}$ and $1 \mathrm{gm}$ of calcium daily. She had family history of tetanic convulsion among her grandmother and three of her siblings and died at their early age. She was on antenatal check up and also consulted with endocrinologist regarding dose of calcitriol. Her pregnancy period was uneventful with Tab calcitriol $(0.25 \mu \mathrm{g}) 2 \mathrm{tab}$ daily and $1 \mathrm{gm}$ of calcium daily. Serum calcium level was normal (1.8mmol/L) and was monitored monthly. Tab calcitriol dose was increased to $1 \mu \mathrm{gm}$ /day from 35wks of pregnancy. She had no tetanic convulsion during her pregnancy period. Elective caesarean section was done on $4^{\text {th }}$ August,09. A female baby of $3.4 \mathrm{~kg}$ was delivered. Serum calcium level of baby was $2.4 \mathrm{mmol} / \mathrm{L}$ after delivery. Mother and baby were healthy at the time of discharge. The mother was discharged with above dose of calcitriol and calcium. 


\section{Discussion}

In normal pregnancy maternal serum concentration of 1,25 $(\mathrm{OH})_{2} \mathrm{D}_{3}$ rises early in the first trimester of pregnancy, remains high and shows a further increase during the third trimester.On the third day after delivery they fall it to nonpregnant level ${ }^{2,3}$. The increased synthesis of $1,25(\mathrm{OH})_{2} \mathrm{D}_{3}$ in the mother may represent an adjustment to the high fetal uptake of calcium into the skeleton, especially in the third trimester ${ }^{4,5}$. In normal pregnancy ionized calcium is actively transported across the placenta ${ }^{6}$. Fetal total and dialysable serum calcium values appear to be slightly higher than maternal values ${ }^{6}$. It has recently been demonstrated in animals that parathyroid hormone (PTH)-related protein (PTHrP) is the fetal equivalent of $\mathrm{PTH}^{7}$. It is believed that fetal PTHrP, which is mainly derived from the placenta during early gestation and from the fetal parathyroid glands during further development ${ }^{7}$, helps maintain the maternal-fetal calcium gradient either alone or in concert with $1,25(\mathrm{OH})_{2} \mathrm{D}_{3}$. Maternal immunoreactive PTH, like other polypeptide hormones, does not cross the placenta. Conflicting result of the PTH concentrations during pregnancy have been reported. Seki et al. ${ }^{8}$ measured low PTH in maternal serum associated with elevated fetal PTHrP. Others ${ }^{9}$ found unchanged with a significant rise in postpartum. In a prospective longitudinal study ${ }^{10}$, parathormone (PTH) concentration increased from first to the second trimester, and return again in third trimester to the level of first. In contrast, PTHrP concentration increased continously throughout pregnancy and lactation.Whether PTH concentration decreases in late pregnancy due to increase in PTHrP production by the placenta is not known. Concerning the treatment of hypoparathyroidism during pregnancy, the absence of PTH impairs metabolism of endogenous vitamin $\mathrm{D}$ to $1,25(\mathrm{OH})_{2} \mathrm{D}_{3}$. Substitution therapy of hypoparathyroidism in this situation requires a compound with immediate and predictable bioavailability . In contrast to prodrugs like cholecalciferol and to tachysterol, calcitriol has a much shorter, dose-indepedendent half life. For example, $50 \%$ of intravenously given radioactive $1,25(\mathrm{OH})_{2}$ $\mathrm{D}_{3}$ is eliminated within 8 minutes from the blood, and $4 \mathrm{hr}$ after administration only $10-16 \%$ is detectable ${ }^{11}$. In case of over treatment, hypercalcemia will resolve within 2 to 7 days. The risk of vitamin D overdosage and subsequent teratogenecity in humans and animals seems to be small as long as the serum calcium and the $1,25(\mathrm{OH})_{2} \mathrm{D}_{3}$ concentrations remain in lower range. In one study outcome of total nine pregnancies complicated by hypoparathyroidism or vitamin D resistant rickets requiring treatment with vitamin $\mathrm{D}$ or its analogues has been published in the literature. No toxicity or teratogenecity was observed, although in some cases very high doses were given. This suggests, based on the still limited available data, that treatment with calcitriol is rather safe. In human there is only one report of a pregnant woman suffering from vitamin D- resistant rickets who received very high doses of calcitriol (17-36 $\mu \mathrm{gm} /$ day).Serum calcium levels of the infant were high after birth, but otherwise the newborn was healthy ${ }^{12}$. In our case the maximum calcitriol dose was $1.00 \mu \mathrm{g} /$ day from $35 \mathrm{wks}$ of pregnancy. No teratogenecity or toxicity was found in the baby and serum Ca level was normal after birth. Pitkin ${ }^{13}$ recommends a daily dosage of calcitriol ranging between 0.5 and $3.0 \mu \mathrm{g} /$ day with advancing gestation to maintain a normal maternal serum calcium level.

\section{Conclusion}

The treatment of choice in hypoparathyroidism in pregnancy is oral calcium supplementation with calcitriol. The calcium concentration should be kept within normal range (between 2.00 and $2.20 \mathrm{mmol} / \mathrm{L}$ ), which generally requires a calcitriol dose between $0.25 \mu \mathrm{g} /$ day and $3.00 \mu \mathrm{g} /$ day. Starting from $0.25 \mu \mathrm{g} /$ day calcitriol and a calcium supplementation of $1 \mathrm{gm} /$ day,the dosage has to be adjusted to the physiological requirements during pregnancy, increasing the dosage after the $20^{\text {th }}$ week of gestation with furher elevation in the last trimester. Because of the short half life of calcitriol, symptomatic tetany at night time may become a problem, which can be controlled by dividng dose. Serum calcium levels should not fall below $1.70 \mathrm{mmol} / \mathrm{L}$.

\section{References}

1. John T. Potts Jr. Diseases of the parathyroid gland and other Hyper and Hypercalcemic disorders. In: Harrison”ûs Principle of Internal Medicine Mc. Graw-Hill companies 1998. p. 2241.

2. Reddy GS. Norman AW. Willis DM. Goltzman D. Guyda H. Soloman S. Regulation pf vitamin D metabolism in normal human pregnancy. J of Clin Endocrin and Meta 1983; 137: 402-409.

3. Cross NA, Hillmann LS, Allen SH, Krause GF, Vieira NE. Calcium homeostasis and bone metabolism during pregnancy.lactation and postweaning:a longitudinal study. Am J of Clin Nutr 1995; 61: 514-523.

4. Kumar R. Cohen WR. Silva P, Epstein FH. Elevated 1, 25dihydroxy-vitamin D plasma levels in normal human pregnancy and lactation. J of Clin Invest 1979; 63: 514-523.

5. Salle BL, Berthezene F, GlorieuxFH, Delvin EE, Berland M, David L et al. Hypoparathyroidism during pregnancy: treatment with calcitriol. J of Clin Endocrin and Metab 1981; 52: $810-813$.

6. Longo LD. Placenter transfer mechanism-an overview. Obstetrics and Gynaecology Annual 1972; 1:103-138. 
7. Kruse K. Der perinatale Kalziumstoffwechsel. Physiologic \& Pathophysiologic. Monatsschrift Kinderheikunde 1992; 140(suppl): 1-7.

8. Seki K, Wada S, Nagata I. Parathyroid hormone- related protein during pregnancy and the perinatal period. Gyn and Obst Invest 1994; 37: 83-86.

9. Gallacher SJ, Fraser WD,Owens OJ, Dryburgh FJ \&Logue FC. Changes in calcitropic hormones and biochemical markers of bone turnover in normal human pregnancy. Euro J. of Endocrin 1994; 131: 369-374.
10. Ardawi MS, Nasrat HA, BA Aqueel HS. Calcium regulating hormones and parathyroid hormone -related peptide in normal human pregnancy and postpartum: a longitudinal study. Euro J Endocrin 1997; 137: 402-409.

11. Rocaltrol product information. Hoffman- La Roche AG.

12. Marx.SJ, Swart EG, Hamstra AI, Deluca HF. Normal intrauterine development of fetus of a women receiving extraordinarily high doses of 1,25-dihydroxyvitamin D. J Clin Endocrin and Metab 1980; 51:1138-1142.

13. Pitkin RM. Calcium metabolism in pregnancy and the perinatal period: a review. Am J Obste and Gyn 1985; 151:99-109. 